\title{
Conciliación y solidaridad con el cambio horario
}

Reconciliation and solidarity with the time change

\author{
Dr. Francisco José MONTES FERNÁNDEZ \\ Ex-profesor Universidad Complutense \\ fjmontes@telefonica.net
}

Resumen: En este trabajo analizamos la controvertida decisión de la unificación de los horarios en el marco de la UE. Una decisión sobre la que no se consiguen poner de acuerdo ni los países miembros en su conjunto, ni cada uno de ellos individualmente, puesto que atañe a la influencia de la luz solar sobre las actividades personales, académicas, comerciales y sociales en general.

\begin{abstract}
Abstrac: In this work we analyze the controversial decision to unify time zones within the EU. A decision on which neither the member countries as a whole, nor each one of them individually, can be agreed on, since it concerns the influence of sunlight on personal, academic, commercial and social activities in general.
\end{abstract}

Palabras clave: Historia, Política, España, Franquismo, Hora legal; Hora oficial, Greenwich; Husos horarios, meridianos, paralelos; Unión Europea, Parlamento europeo, Comisión Europea, Luz solar.

Keywords: History, Politics, Spain, Franco's Regime, Legal Time, Official Time, Greenwich, Time Zones, Meridian, Terrestrial parallel, European Union, European Parlament, European Commission, Sunlight.

\section{Sumario:}

\section{Introducción.}

II. Calendarios.

III. Desarrollo histórico. 
IV. Situación actual.

V. Conclusiones.

VI. Bibliografía.

6.1. Directivas de la Unión Europea.

6.2. Otras obras y artículos.

Recibido: noviembre 2020.

Aceptado: enero 2021. 


\section{INTRODUCCIÓN}

Cada día me apasiona más la historia. Da igual la época porque cualquier período en el que nos detengamos surgen hechos desconocidos que dan pie para que algún historiador pueda ponerse a trabajar, bien sea para una tesis, un trabajo financiado, una conferencia o un premio o similar o simplemente por curiosidad. Así se va tejiendo la historia, a base del esfuerzo de unos pocos más o menos conocidos y reconocidos que. han utilizado una parte de su vida para investigar y profundizar en un hecho lo suficientemente relevante para ellos. Cualquier esfuerzo, cualquier aportación es importante y trascendental para ir avanzando en el conocimiento de nuestra historia.

Pierre Vilar ${ }^{1}$ afirma: “¿Por qué quiere usted hacer historia? Respuesta casi unánime: para conocer el pasado con objeto de comprender el presente". Más tarde, añade: "Comprender el pasado es dedicarse a definir los factores sociales, descubrir sus interacciones, sus relaciones de fuerza, y a descubrir, tras los textos, los impulsos (conscientes, inconscientes) que dictan los actos. Conocer el presente equivale, mediante la aplicación de los mismos métodos de observación, de análisis y de crítica que exige la historia, a someter a reflexión la información deformante que nos llega a través de los medios. "Comprender" es imposible sin "conocer". La historia debe enseñarnos, en primer lugar a leer un periódico".

José Luis Ibáñez manifiesta que "La misión de los historiadores es comprender las diferencias entre el presente y el pasado y explicar por qué son importantes"

Me interesa la historia del mundo, las relaciones internacionales y no quiero decir lo que me apasiona la historia de España que es una de las más ricas del mundo, simplemente porque, como se recordará, España fue "El Imperio donde nunca se ponía el sol"2.

Para una persona normal, de las que somos tantos millones en el mundo (o eso se supone), que no destacamos por nada, ni para bien ni para mal, existen

\footnotetext{
${ }^{1}$ VILAR, P., Iniciación al vocabulario del análisis histórico. Crítica, Barcelona 1980, p. 12.

2 IBÁÑEZ SALAS, J.L., La Historia el relato del pasado. Silex, Madrid 2020.
} 
pequeñas o no tan pequeñas dificultades para el desarrollo de la vida cotidiana, aspectos del día a día que nos complican extraordinariamente la vida personal, profesional y social. Tal es el caso del cambio de horario, tema controvertido donde los haya y donde ni en España, ni siquiera en la Unión Europea han sido capaces de ponerse de acuerdo.

Al mismo tiempo, hay problemas que aunque los Estados desean llegar a un consenso, son tales las diferencias existentes entre ellos, que no siempre es posible alcanzar una solución que satisfaga a todos ellos. Tal es el caso de la actual Unión Europea que queda muy lejos y parece que cada vez más lejos de aquella unión pergeñada por Robert Schumann. El Ministro francés de Asuntos Exteriores manifestó, tras la Segunda Guerra Mundial, la necesidad de que para alcanzar la pretendida unión europea que venían exigiendo numerosos movimientos de su época, debía antes lograrse una solidaridad de hecho. Es decir, solamente a través de realizaciones concretas de carácter económico podía llegarse a una integración política entre los Estados de la Europa occidental. Día a día vamos observando el interés de los países miembros de ir a lo que les interesa poniendo por encima del interés general, sus intereses particulares, con un descarado egoísmo, claro que los políticos actuales son un poco diferentes a los que hicieron todo lo posible para ir aumentando el número de miembros, lo cual no quiere decir que haya intereses comunes, sino algunos muy enfrentados, como puede ser el caso de Turquía por culpa de su religión, por poner un ejemplo. Tampoco eran santos los que crearon la entonces CEE, Comunidad Económica Europea. Pasados los años, hemos podido ir conociendo sus vidas políticas y personales (en muchos casos están sus nombres en el ánimo de todos), y aún lo seguimos viendo en declaraciones intempestivas a la prensa. Dicen que la política es el arte de lo imposible, aunque a veces lo imposible es hacer política con los mimbres de que disponemos.

El espíritu de la declaración de Schumann no solo no perdió actualidad en el proceso de integración europeo, sino que se convirtió en el principio informador de su evolución. Esta idea tan clara que tenían los fundadores de la Comunidad Europea del Carbón y del Acero, la CECA, parece que se ha ido diluyendo a medida que se van incorporando más miembros a la Unión, donde se anteponen los intereses de cada Estado a los generales de la UE.

Como bien se sabe, el cambio de hora afecta al mundo, es decir a todo el globo terráqueo. Es una convención internacional por la que se rigen las horas en cada país, las telecomunicaciones en general, la navegación de todo tipo, los ferrocarriles, los transportes, incluso la sanidad o la educación, el comercio internacional y nacional, etc., etc. 
Los gobiernos de todos los países adoptan lo que se denomina hora oficial, so pretexto de ahorrar energía en verano o invierno, según corresponda. Esta medida que parece sencilla es motivo de numerosos desacuerdos en países como el nuestro con autonomías tan meridionales como Canarias o tan septentrionales como Galicia. En primer lugar, no debe olvidarse que España no está tan recta como nos indican los mapas al uso, sino que en el contexto europeo está completamente inclinada siendo el punto más nórdico el Islote de Estaquín de Sigüelos al norte de Estaca de Bares, el famoso cabo.

Es evidente que este adelantamiento o atraso influye en la vida de todos los españoles en primer lugar y nada tiene que ver la vida de un canario con la de un gallego.

La Tierra está dividida en 24 husos horarios, o dicho de otro modo un huso horario es cada una de las 24 áreas en que se divide la Tierra por un meridiano y en la que rige por convención el mismo horario. Como consecuencia de pasar por el medio de España el meridiano 0 o de Greenwich, que es el meridiano origen de las longitudes, ésta queda dividida en 12 husos hacia el Este y 12 hacia el Oeste. Cada huso horario comprende $15^{\circ}$ de longitud, equivalente a 1 hora o lo que tarda en recorrer el sol un meridiano, en consecuencia cada $15^{\circ}$ de longitud habrá una hora diferente y un huso diferente. A esta hora se la denomina hora legal.

El tiempo universal coordinado (UTC) es la escala de tiempo basada en el segundo, definida y recomendada por el CCIR (Comité Consultivo Internacional de Radiocomunicaciones), y mantenida por la Oficina Internacional de la Hora (BIH).

Para la mayoría de los fines prácticos, el UTC es equivalente a la hora solar media en el meridiano origen $\left(0^{\circ}\right.$ de longitud $)$, anteriormente expresada en GMT (Greenwich Meridian Time).

En Europa se utiliza con mucha frecuencia la hora CET (Central European Time). La Hora Central Europea u Hora de Europa Central, también es conocida por otros nombres, como Hora Europea Media (Middle European Time). En el pasado se conocía como Hora de Berlín.

Los siguientes países y territorios utilizan la Hora Central Europea sólo durante el invierno, desde las 1:00 (UTC) del último domingo del mes de octubre hasta las 1:00 (UTC) del último domingo del mes de marzo. El resto del año utilizan la Hora Central Europea de Verano (CEST, Central European Summer Time), que es UTC+2. 
- Albania, desde 1914

- Alemania, desde 1893

- Andorra, desde 1946

- Austria, desde 1893

- Bélgica, en los años 1914-19 y desde 1940

- Bosnia y Herzegovina, desde 1884

- Croacia, desde 1884

- Dinamarca, desde 1894

- Eslovaquia, desde 1890

- Eslovenia, desde 1884

- España, desde 1946 (excepto las Islas Canarias)

- Francia (metropolitana, desde 1940 excepto en 1944-45)

- Gibraltar, desde 1957

- Hungría, desde 1890

- Italia, desde 1893

- Liechtenstein, desde 1894

- Luxemburgo, en los años 1904-18 y desde 1940

- Macedonia, desde 1884

- Malta, desde 1893

- Mónaco, desde 1945

- Montenegro, desde 1884

- Países Bajos, desde 1940

- Noruega, desde 1895

- Polonia, en los años 1915-18 y desde 1922

- República Checa, desde 1891

- San Marino

- Serbia, desde 1884

- Suecia, desde 1900

- Suiza, desde 1894

- Túnez

- Vaticano

Antes de la Segunda Guerra Mundial, Lituania utilizaba la CET entre los años 1920-1940. Durante la guerra, se utilizó en todos los territorios ocupados por Alemania. En Francia, Bélgica, Países Bajos y Luxemburgo la CET se impuso a partir de 1940. Después de la guerra, España, Mónaco, Andorra y Gibraltar adoptaron la CET.

Irlanda y el Reino Unido de forma experimental se incorporaron a la CET en los años 1968-1971; sin embargo, este experimento se mostró impopular y tuvo una duración breve, principalmente debido al incremento del número de accidentes en carretera (muchos de ellos eran niños de camino al colegio) en 
las oscuras mañanas del invierno. Portugal utilizó la CET en los años 19661976 y 1992-1996.

Estos países utilizan la Hora Central Europea durante todo el año:

- Algeria

- Angola

- Benín

- Camerún

- Chad

- Gabón

- Guinea Ecuatorial

- Namibia

- Niger

- Nigeria

- República Centroafricana

- República Democrática del Congo (parte occidental)

- República del Congo

La mayor evidencia de este hecho es la noche del 31 de diciembre, momento en el que han celebrado el año nuevo en Australia y Nueva Zelanda, mientras en España nos faltan 12 horas para llegar y eso que Nueva Zelanda tiene varias zonas horarias. Así por ejemplo, a las 00.00 del jueves en Wellington (NZ) son las 12.00 del miércoles en Madrid.

\section{CALENDARIOS}

Como se sabe, hay tres grandes tipos de calendarios: los antiguos (egipcio, babilónico, griego, maya y romano), los tradicionales (chino e hindú) y los modernos (musulmán y gregoriano).

El calendario egipcio combina el calendario lunar (fases de la luna) y el calendario agrícola. Consta de 365 días dividido en 12 meses de 30 días más 5 días (epogámenos). Tenía tres estaciones de 4 meses cada una. Los meses no tenían un nombre particular, sino que se designaban con el lugar que ocupaban en la estación; ejemplo: el mes $3^{\circ}$ de la inundación.

El calendario babilónico se basaba en el lunar, constando de 354 días divididos en 12 meses de 29 o 30 días. Los meses tenían nombres y de ellos derivan los meses judíos, que en su calendario añaden un mes cada 2 o 3 años. 
El calendario griego se basaba también en el lunar con 354 días, divididos en 12 meses alternando los de 29 y 30 días para ajustarse mejor a las fases de la luna. Los meses recibían diferentes nombres que variaban de Atenas a Macedonia.

Los calendarios mayas eran una sucesión indefinida de días, ordenados arbitraria e independientemente de los fenómenos astronómicos. Existían dos: el ritual de 260 días y el solar de 365, distribuidos en 18 meses de 20 días y 1 mes denominado nefasto de 5 días.

Los romanos utilizaron tres calendarios: el primitivo de Rómulo (con 304 días en 10 meses, de los que 4 eran de 31 días y 6 de 30); el lunar de Numa Pompilio, con 355 días distribuidos en 12 meses; y el juliano de Julio César, una variante del anterior para ajustarlo al año solar con 365,25 días, en el que se fijaron 3 años de 365 días y uno, bisiesto, de 366 . Este calendario ha estado vigente hasta el siglo XX en los países de tradición ortodoxa.

El calendario chino fue empleado desde el año 1025 a.J.C. hasta la revolución de 1911. Estaba basado en el sol y la luna, constaba de un ciclo de 19 años dividido en 12 años comunes, de 12 meses lunares, (con nombres de animales) de 29 o 30 días y 7 años de 13 meses de 383 o 384 días.

El calendario hindú fue originariamente lunar, pero luego fue modificado con datos astrológicos, convirtiéndose en lunar-solar. Constaba de 1 año de 6 estaciones con 12 meses que coincidían con el tiempo que el Sol tarda en recorrer cada signo del Zodíaco, comenzando el año con el signo de Aries.

Dentro de los calendarios modernos se encuentra el musulmán, basado en el calendario lunar con 354 ó 355 días en un ciclo de 30 años y 12 meses de 30 ó 29 días alternativos. Respecto al calendario gregoriano, el año musulmán comienza entre 10 y 12 días más tarde cada año. Los musulmanes empiezan a contar las fechas (años) a partir del 16 de julio del 622 de la era cristiana.

Por último, el calendario gregoriano que se debe al Papa Gregorio XIII. Es una reforma del juliano para ajustarlo al año solar o trópico y hacerlo coincidir con las estaciones. Consta de 365 días divididos en 12 meses de 30 ó 31 días y 1 de 28 días. Establece un año bisiesto cada 4, siguiendo la norma juliana, pero los años que acaban en dos ceros son años comunes de 365 días excepto el año 1600 y el 2000 que se consideran bisiestos. A pesar de todo, existe una diferencia entre el año gregoriano y el trópico de 0,0003 días, que se regulará en el 4317, año que tendrá un día menos. Es el calendario universal para las actividades civiles, por consiguiente, toda fecha que se utilice en relación con las radiocomunicaciones deberá emplearse de conformidad con el Calendario Gregoriano. 
Si en una fecha el mes no está indicado de forma completa ni abreviada, se expresará de forma totalmente numérica, según una secuencia fija de cifras en la que cada grupo de dos cifras representará el día, el mes y el año.

Salvo indicación contraria, siempre que se emplee una hora especificada en actividades internacionales de radiocomunicación, se aplicará el Tiempo Universal Coordinado (UTC), y se representará en un grupo de cuatro cifras (0000-2359). La abreviatura UTC deberá utilizarse en todos los idiomas.

En España, la Sección de Hora del Real Instituto y Observatorio de la Armada en San Fernando está constituida por tres Servicios: Hora, Cronometría Naval y Electrónica y Calibración.

Este organismo, tiene como misión principal el mantenimiento de la unidad básica de Tiempo, declarado a efectos legales como Patrón Nacional de dicha unidad, así como el mantenimiento y difusión oficial de la escala "Tiempo Universal Coordinado" (UTC(ROA)), considerada a todos los efectos como la base de la hora legal en todo el territorio nacional (R. D. 23 octubre 1992, núm. 1308/1992).

Su laboratorio está declarado "asociado al Centro Español de Metrología" (R. D. 23 octubre 1992, núm. 1308/1992).

Las actividades de los tres servicios de la Sección están interrelacionadas y son las que se indican a continuación:

1. Mantenimiento del patrón de Tiempo y de la hora legal española.

2. Difusión de la hora legal española.

3. Participación en foros científicos internacionales.

4. Actividades de ámbito nacional.

5. Otros cometidos asignados:

6. ¿Qué hora es?

7. Cambios de hora oficial en España desde 1918

En España, el Instituto para la Diversificación y Ahorro de la Energía (IDATE) estima que el adelanto veraniego supone un ahorro del 5\% en el gasto iluminación de los hogares, y del $3 \%$ en el consumo de aire acondicionado en servicios y comercios; en total cerca de 11.500 millones de pesetas anuales ${ }^{3}$.

\footnotetext{
${ }^{3}$ SAMPEDRO, J., La hora del cambio. El País, 26 de octubre de 1996, 27.
} 


\section{DESARROLLO HISTÓRICO}

Manuel Miguel Gámez Mejías ${ }^{4}$, desde mi personal punto de vista es el investigador que mejor y con mayor profundidad ha tratado el tema y a él me remito, además de a Pere Planesas ${ }^{5}$. Ambos han realizado interesantes y muy completas investigaciones sobre el cambio de horario.

La idea es antigua. Ya "en 1784, el inventor y político estadounidense Benjamin Franklin afirmaba que si la población se despertaba una hora más temprano en verano, se ahorraría una cantidad importante de velas"6.

A mediados del siglo XIX, el desarrollo de los ferrocarriles obligó a puestas en común de los horarios de las líneas férreas, para unificar las horas de llegadas y salidas de los trenes que no se podían llevar a cabo a través de las horas locales, puesto que originaban multitud de errores.

También contribuyó a la unificación horaria el telégrafo.

La medida se aplicó experimentalmente en la Primera Guerra Mundial, para reducir el gasto de combustible, y como consecuencia de la crisis económica de 1917 en España se adopta otra vez. Así transcurren los años, muy influidos por la política y el cambio de horario y continúan los cambios horarios durante la Guerra Civil en los dos bandos, de forma que al final de la guerra hay dos horas legales en España.

Fue en la década de 1970 cuando, con la primera crisis del petróleo, algunos países decidieron adelantar el reloj con el fin de aprovechar mejor la luz del sol y consumir menos electricidad.

España, como se puede comprobar en el cuadro final de elaboración propia, comenzó de nuevo con los cambios horarios en 1974.

${ }^{4}$ GÁMEZ MEJÍAS, M.M., "Origen, evolución y futuro de la determinación normativa de la hora legal en España y la Unión Europea”, en Revista de Administración Pública (Madrid), $n^{\circ} 177$ (Septiembre - diciembre 2008) 377-417.

5 PLANESAS, P., "La hora oficial en España y sus cambios", en Anuario del Observatorio Astronómico de Madrid, (2013) 373-444.

${ }^{6}$ R.D., "Cambio al horario de invierno: el domingo 25 de octubre a las 3 serán las 2", en Diario de Sevilla, 23 octubre 2020. 


\section{SITUACIÓN ACTUAL}

Como respuesta a las múltiples iniciativas ciudadanas, el Parlamento Europeo pidió a la Comisión, en febrero de 1918, "que evaluara la conveniencia de mantener el cambio de horario y que, en función de sus conclusiones, propusiera una revisión de la directiva vigente".

La Comisión efectuó una evaluación y recibió 4,6 millones de respuestas, el $84 \%$ favorables a suprimir el cambio. A continuación, presentó una propuesta legislativa. Los colegisladores, el Parlamento y el Consejo, deberán ponerse de acuerdo para que el texto pueda entrar en vigor.

La UE unificó el procedimiento del cambio de hora en 1980. De acuerdo a la norma vigente, "los países deben cambiar al horario de verano el último domingo de marzo, y de vuelta al horario estándar el último domingo de octubre”.

La Comisión Europea en agosto de 2018 concluyó, tras el resultado de una encuesta a través de internet, eliminar el cambio de hora en el conjunto de la Unión Europea, dado que era eso lo que deseaba el $84 \%$ de los encuestados y habían votado en ese sentido. Jean-Claude Juncker, entonces presidente de la Comisión Europea, afirmó que si ese era el deseo de los europeos, de los 28, pues que se llevaría a cabo, aunque señaló que propondría mantener el horario de verano, si esa era la decisión de cada país. "Solo en dos países Chipre y Grecia ha vencido la opción de seguir con el cambio de hora, aunque ello no implica que queden fuera de la reforma" 7 .

El Parlamento Europeo apoyó, el martes 26 de marzo de 2019, terminar con el cambio de hora estacional del verano en la UE en 2021, pero dando la posibilidad a cada país de elegir si desea mantener el horario de verano o el de invierno.

Los Estados miembros que decidan quedarse con el horario de verano cambiarían por última vez el reloj en marzo de 2021, mientras que los que elijan el horario de invierno tendrían que volver a cambiar la hora en octubre de 2021. El texto fue aprobado por 410 votos a favor, 192 en contra y 51 abstenciones ${ }^{8}$. Como se puede observar por el análisis de los resultados, no hubo unanimidad sino que el resultado estuvo peleado por la falta de acuerdo entre los países miembros y lo comprendo perfectamente. Cualquiera que lo

\footnotetext{
7 SÁNCHEZ, A., "Bruselas propondrá la desaparición del cambio de hora en la UE", en El Pais, 31 agosto 2018.

8 "El Parlamento respalda acabar con el cambio de hora en 2021". Nota de Prensa. Parlamento Europeo, 26 marzo 2019.
} 
medite un poco y lo compare con España, por citar un ejemplo, se dará cuenta lo complicado que es, que por cierto en este año de 2020 está aliada con Francia y Alemania. Algunos autores dicen que Francia se quiso poner en la misma hora que Alemania, y España adoptó el criterio de ponerse en el mismo horario de Alemania con división de opiniones, unos afirman que fue un regalo que Franco quiso hacer a Alemania y otros para ponerse de acuerdo con Francia.

Por supuesto, Portugal fue una vez más dada de lado e ignorada, pese a que nuestra relación con nuestro vecino país es muy estrecha en lo que respecta al transporte por carretera y al turismo, mientras que nuestra relación ferroviaria es más bien escasa y no han querido, quizá, por sentido común y problemas económicos, unirse a España con el AVE que solo llegará a la frontera portuguesa. De nuevo apareció una discrepancia notable: los españoles quieren unir Madrid con Lisboa y los portugueses Lisboa, Oporto y Vigo porque alegan que sus mayores relaciones con los españoles lo son con los gallegos y Galicia, so pretexto que la conexión Madrid-Lisboa se realiza por avión. Todo esto ocurrió en noviembre del 2020 y, con anterioridad, en la XXXI Cumbre HispanoPortuguesa del pasado 10 de octubre del mismo año?.

Tenemos que dejar claro que debería ser el propio país el que decidiese adoptar un determinado horario, de acuerdo con sus necesidades y las relaciones con los países de su entorno. Así mismo, debería respetarse el mapa continental. Al final del trabajo se ofrece el mapa (elaborado por El País), donde claramente se puede observar la ilógica situación actual en la que, por citar un ejemplo, Helsinki tiene la misma hora que París o Madrid, mientras que Portugal tiene diferente hora que España y la misma que Londres, como debería tener España. Canarias está en el mismo meridiano que la capital de Islandia, Reykiavik, por lo que deberían coincidir en horario y no lo están. Canarias lleva 1 hora de adelanto a la capital de Islandia. También las opiniones entre los españoles difieren muchísimo entre canarios y murcianos, por poner un ejemplo, o entre gallegos y catalanes.

La consulta de Bruselas permitió recoger opiniones de los votantes y se llegó a la conclusión de que el cambio de horario molestaba sobremanera a los europeos que achacan a los cambios de hora los efectos negativos en su vida personal, principalmente en forma de cansancio, problemas de sueño o falta de concentración.

Aunque mi opinión personal no afecte al resultado de la encuesta, puedo manifestar que no he sentido ninguno de estos efectos, eso si los siento si

\footnotetext{
${ }^{9}$ LÓPEZ, P., "Portugal desoye a Sánchez: sustituye el AVE a Madrid por la conexión con Galicia", en El Confidencial, 15-11-2020.
} 
duermo menos de 8 horas pero por estar ocupado realizando otras actividades como la preparación de las clases o estar leyendo libros actuales sobre la materia que explico (además de su elevado coste económico, porque desde que el libro está a disposición de los lectores en las bibliotecas de las facultades pasan semanas y si son de fuera del país meses, por lo que se hace imprescindible adquirirlos en alguna de las librerías que disponen de todas las novedades a las pocas horas de distribuirlas las editoriales y no me refiero a Planeta o análogas, dedicadas a los llamados más vendidos, sino editoriales con prestigio y que editan libros de gran interés para historiadores como Marcial Pons, Crítica, Taurus, Alianza, Espasa, antes de su adquisición por Planeta, y la propia Planeta cuando edita libros de interés histórico que los ha editado y muy buenos).

\section{RAZONES A FAVOR DE CAMBIAR EL HORARIO EN VERANO.}

Como hay muchas publicaciones que indican más o menos las mismas causas con distintas palabras, he seleccionado el artículo que recojo a continuación en el que se reúnen las conclusiones que ya aparecían en diversas publicaciones. Es la más reciente sobre estas dos preguntas que se formula la mayoría de la población mundial:

1. Supuesto ahorro de energía que cada vez es más discutido. "Los partidarios del cambio destacan el ahorro de 440 gigawatios de alumbrado, es decir, lo que consumen unos 800.000 hogares y permitió que la potencia se aumentara en 3,5 gigawatios, aliviando el desafío energético que representan los picos de consumo", sin embargo tales ahorros energéticos cada vez son más cuestionados porque según los expertos no es una realidad el supuesto ahorro energético con las nueva bombillas led, placas solares y nuevas formas de energía como la eólica, marina, etc. El debate continúa sin que nadie se atreva a dar cualquier solución por definitiva.

\section{RAZONES EN CONTRA DE CAMBIAR EL HORARIO EN VERANO.}

La razón de este cambio, como, se sabe, es para adaptar la jornada laboral a las horas de luz natural y al ritmo de actividad mayoritario de toda la población afectada por el cambio.

1. "Efectos negativos para la salud entre los que se encuentra el riesgo de sufrir accidentes de tráfico, por el sueño"10.

2. "Altera la producción de hormonas, como la serotonina, que se produce al recibir el sol nuestro organismo"11.

${ }^{10}$ OSUNA, I., "Saber vivir TVE", 23 octubre 2020. 
3. "Afecta al ritmo cardíaco"12.

4. "Favorece los trastornos del sueño y, por tanto, aumenta la somnolencia diurna y la dificultad para concentrarse, y reduce el rendimiento intelectual" ${ }^{\text {"13 }}$. Los expertos en sueño afirman que es más saludable el horario de invierno, porque amanecería una hora más tarde.

5. "Causa irritabilidad, fatiga, mareos, problemas digestivos"14.

6. "Aunque la mayoría de las personas se adaptan al cambio de hora en unos días o una semana como mucho, estos trastornos pueden prolongarse o ser más intensos en niños, ancianos o personas que sufran enfermedades, problemas emocionales o psicológicos" ${ }^{\text {"15 }}$.

7. "Empezar la jornada de noche puede disminuir el rendimiento escolar o laboral". La luz de la mañana juega un papel clave en la producción de melatonina por la noche, una hormona fundamental para facilitar el sueño. Por eso, la falta de luz a primera hora podría causar un peor descanso nocturno.

Por otro lado, el día también se alargaría y anochecería una hora más tarde. Y esto, según los expertos, puede fomentar la prolongación de los horarios laborales y de las actividades de ocio y contribuir a que todavía nos vayamos a dormir más tarde" $"$.

\footnotetext{
${ }^{11}$ Osuna, o.c.

${ }^{12}$ Osuna, o.c.

${ }^{13}$ Osuna, o.c.

${ }^{14}$ Osuna, o.c.

${ }^{15}$ Osuna, o.c.

${ }^{16}$ Osuna, o.c.
} 


\begin{tabular}{|c|c|c|c|}
\hline \multicolumn{4}{|c|}{ LOS RESULTADOS DE LA CONSULTA POR EL CAMBIO HORARIO } \\
\hline & \multirow{2}{*}{$\begin{array}{c}\text { Participación } \\
\text { (\% de la población } \\
\text { de cada país) }\end{array}$} & \multicolumn{2}{|c|}{$\begin{array}{c}\text { Respecto al cambio horario, ¿qué opción } \\
\text { preferiría? (\%) }\end{array}$} \\
\hline & & Abolirlo & Mantenerlo \\
\hline \multicolumn{2}{|l|}{ UE - 28} & 84 & 16 \\
\hline Alemania & $3,79 \%$ & 84 & 16 \\
\hline Austria & $2,94 \%$ & 77 & 23 \\
\hline Luxemburgo & $1,78 \%$ & 79 & 21 \\
\hline Finlandia & $0,96 \%$ & 95 & 5 \\
\hline Estonia & $0,94 \%$ & 85 & 15 \\
\hline Chipre & $0,88 \%$ & 47 & 53 \\
\hline Eslovenia & $0,73 \%$ & 87 & 13 \\
\hline Eslovaquia & $0,6 \%$ & 80 & 20 \\
\hline Francia & $0,59 \%$ & 84 & 16 \\
\hline Rep. Checa & $0,59 \%$ & 83 & 17 \\
\hline Bélgica & $0,55 \%$ & 84 & 16 \\
\hline Croacia & $0,52 \%$ & 90 & 10 \\
\hline Suecia & $0,48 \%$ & 88 & 12 \\
\hline Letonia & $0,39 \%$ & 85 & 15 \\
\hline Grecia & $0,34 \%$ & 44 & 56 \\
\hline Lituania & $0,34 \%$ & 91 & 9 \\
\hline Polonia & $0,34 \%$ & 95 & 5 \\
\hline Portugal & $0,33 \%$ & 85 & 15 \\
\hline Malta & $0,25 \%$ & 54 & 46 \\
\hline Irlanda & $0,24 \%$ & 88 & 12 \\
\hline Hungría & $0,21 \%$ & 90 & 10 \\
\hline España & $0,19 \%$ & 93 & 7 \\
\hline Bulgaria & $0,18 \%$ & 84 & 16 \\
\hline Holanda & $0,16 \%$ & 79 & 21 \\
\hline Dinamarca & $0,11 \%$ & 81 & 19 \\
\hline Italia & $0,04 \%$ & 66 & 34 \\
\hline Rumania & $0,04 \%$ & 78 & 22 \\
\hline Reino Unido & $0,02 \%$ & 82 & 18 \\
\hline & & & EL PAIS \\
\hline
\end{tabular}




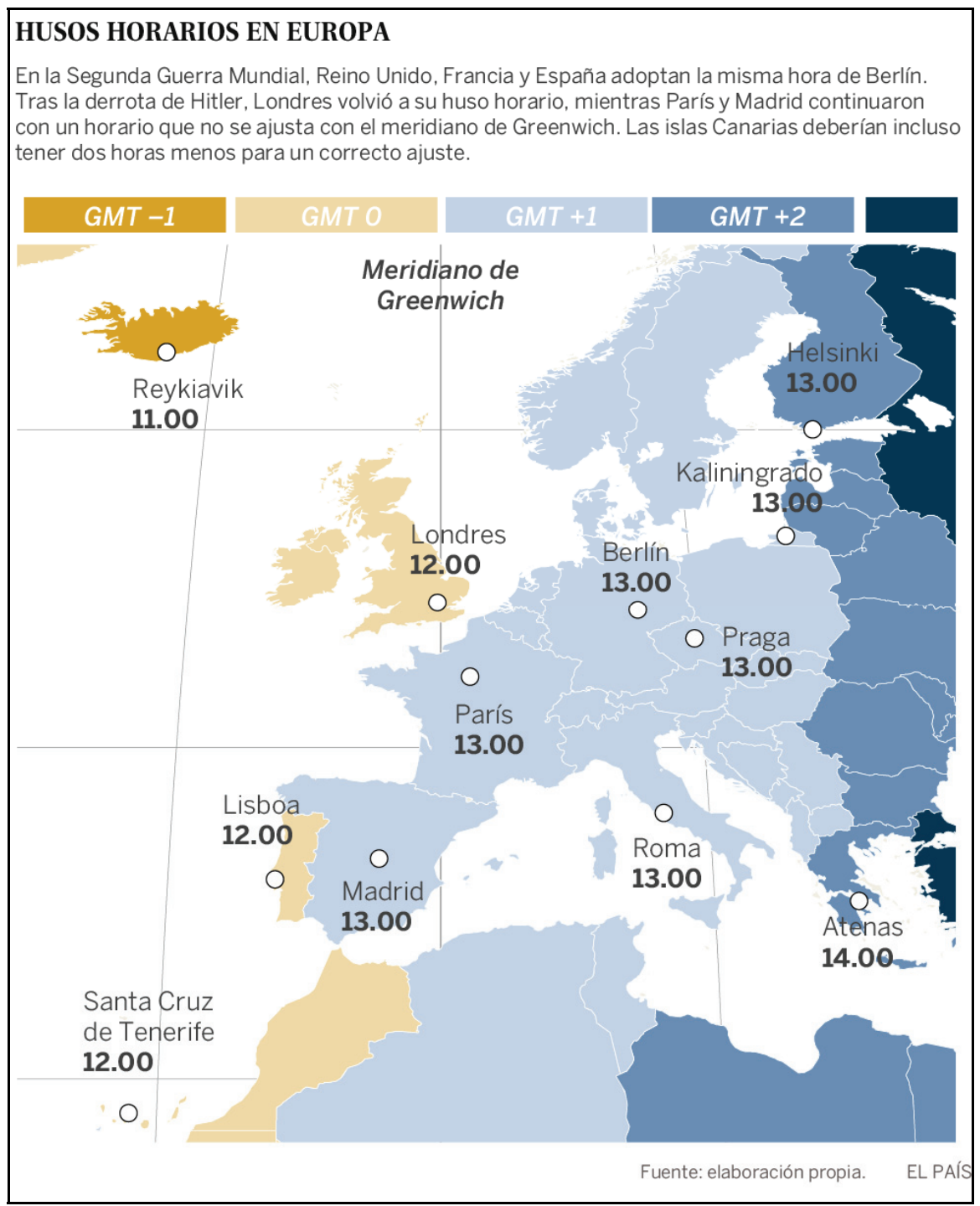

\section{CONCLUSIONES}

He redactado este trabajo entre la primera y la segunda ola del Covid-19, es decir, cuando el virus ya nos había mostrado su peor cara y empezamos a tomar conciencia de la debilidad sobre la que está basada la actividad humana. Son momentos muy difíciles en los que debemos reflexionar sobre qué sociedad queremos que se imponga después de este susto universal. Toda nuestra vida va a estar dividida en un antes y un después del Covid. 
Pues bien, partiendo de nuestra situación geográfica (país europeo del sur, del Mediterráneo, del Atlántico y del Cantábrico) no podemos enfocar nuestra sociedad, nuestra riqueza, nuestros objetivos en general únicamente en una economía basada en el turismo. La fragilidad de esos planteamientos ha quedado sobradamente demostrada en esta crisis.

Por ello, considero que hemos de reeducarnos para enfocar nuestra atención en actividades más sólidas que no dependan tanto de los factores meteorológicos (el sol y la playa) y, en consecuencia, sean más estables (tecnología, investigación, cultura...).

El hecho de estar a las puertas de establecer un horario oficial que marque nuestra vida, supone darnos una oportunidad para modificar nuestros hábitos, más propios de una república bananera que de un país europeo occidental.

El horario de invierno actual, no solo es más acorde a nuestra ubicación geográfica sino que nos invita a adelantar nuestros hábitos: levantarnos y acostarnos antes, comer y cenar antes, un horario laboral más acorde con nuestros vecinos del norte y del oeste, siempre olvidados, y, en definitiva, la creación de una nueva vida personal, laboral y social más responsable y menos arriesgada.

Bien claro ha quedado que los cambios horarios son competencia de la Unión Europea, pero su mantenimiento o eliminación debe ser debatida, negociada y consensuada entre los gobiernos de los países miembros. No debe olvidarse que cada país es soberano para decidir su horario

\section{La Ley debe ser aprobada en todo caso por el Parlamento Europeo.}

Teniendo en cuenta la situación actual con el coronavirus, el cambio horario ha dejado de ser un problema primordial, para ser el coronavirus y sus vacunas lo que distrae la atención de la Unión Europea en su conjunto. Aprobado ya el pertinente presupuesto, además del tiempo que lleva el debate en el seno de los países miembros, para llegar al acuerdo definitivo que pasa por mantener el horario de invierno, como más favorable para la vida biológica de sus habitantes, dado que con el horario de invierno anochece y amanece más temprano, disponiendo de menos luz solar por las tardes, lo que a la postre significa la mejor adaptación entre la luz natural y la vida de los ciudadanos en general.

En España, el ejecutivo puso en marcha en 2018 una comisión de expertos para estudiar y poner sobre el papel las ventajas y desventajas de mantener el cambio horario. Tras meses de trabajo, cosa extraña en nuestro país no llegaron a ningún acuerdo. iiiiSiempre igual en España!!!! 
La solución no parece que llegará antes de 2022, porque a estas alturas de 2020 ya es imposible evitar los cambios en el próximo año, que supongo será el domingo 28 de marzo de 2021, cuando se adelanten los relojes una hora además, ni se habla del problema y si se debate es en el más absoluto de los secretos.

Tampoco hay que olvidar el cambio de 1940 con Franco cuando se adelantó la hora y no se atrasó quedando España, Francia, Alemania y Reino Unido con el mismo horario, pero al terminar la guerra Reino Unido volvió a su horario habitual. Ahora queda la situación de España, Francia, Bélgica y Holanda

España, por lógica, debería tener el mismo horario que Reino Unido, Canarias y Portugal, de acuerdo con el uso horario que se puede observar en el mapa de usos horarios y esa es otra, que ha originado muchos conflictos en las reuniones por citar dos ejemplos entre autonomías de Galicia y Cataluña, uno más para añadir a la lista de desencuentros.

He titulado el artículo: "Conciliación y solidaridad con el cambio horario" porque cada país europeo parece que cada vez es más defensor de sus ideas, importándole muy poco o nada el daño que puede causar a sus vecinos de fronteras, tal y como estamos observando con el coronavirus y todo lo que lleva consigo esta pandemia. Parece que es imposible llegar a un acuerdo en el que se concilien los intereses de cada Estado en función del bien común de todos, teniendo en cuenta la política de cesiones o concesiones que todos los estados deben realizar para que impere el bien común, por encima de los intereses particulares de cada uno. Y al mismo tiempo, también debemos tener igualdad y solidaridad, para obtener un resultado que sin beneficiar especialmente a ninguno, tampoco le perjudique de tal forma que sea inasumible para él.

Repito para que quede claro, nuestro huso horario es el de Europa Central $(\mathrm{GMT}+1)$ en invierno y GMT+2 en verano, cuando se adelanta otra hora, pero no es el real que nos corresponde por el huso horario donde está nuestro país, España, que debería ser el GMT +0 , igual que Londres y Lisboa

\section{BIBLIOGRAFÍA}

\subsection{Directivas de la Comunidad Europea}

- Directiva 80/737/CEE del Consejo, de 22 de julio de 1980, relativa a las disposiciones relativas al horario de verano (Fecha publicación en el DOCE: 22-07-1980). (Derogada). 
- Segunda Directiva horario verano 82/399/CEE del Consejo de 10 de junio 1982. (Derogada).

- Tercera Directiva 84/634/CEE del Consejo, de 12 de diciembre de 1984, relativa a las disposiciones sobre el horario de verano (DO L 331, 19-121984). (Derogada).

- Directiva 85/582/CEE del Consejo de 20 de diciembre 1985). (Derogada).

- Dictamen del Comité Económico y Social sobre la "Propuesta de cuarta Directiva del Parlamento Europeo y del Consejo relativa a la hora de verano".

- Cuarta Directiva 88/14/CEE del Consejo de 22 de diciembre de 1987. (Derogada).

- Dictamen del Comité Económico y Social sobre la "Propuesta para una quinta directiva del consejo relativa a las disposiciones sobre la hora de verano $27-10-1988$ ?

- Quinta Directiva 89/47/CEE del Consejo de 21 de diciembre de 1988. (Derogada).

- Sexta Directiva del Consejo de 26 de marzo de 1992(92/20/CEE). (Derogada).

- Séptima Directiva 30 mayo 1994. (Derogada).

- Dictamen del Comité Económico y Social sobre la "Propuesta de octava Directiva del Parlamento Europeo y del Consejo relativa a las disposiciones sobre la hora de verano", 25-09-1996.

- Octava Directiva 97/44/CE del Parlamento Europeo y del Consejo de 22 de julio de 1997 (DO L 206, 1-8-1997). (Derogada).

- Propuesta de Directiva del Parlamento Europeo y del Consejo relativa a la hora de verano (2000/C 337 E/18) DO (C 337/E/136). 28-11-2000.

- Directiva 2000/84/CE del Parlamento Europeo y del Consejo, de 19 de enero de 2001, relativa a las disposiciones sobre la hora de verano (DO L 31, 2-2-2001). VIGENTE.

- "El Parlamento respalda acabar con el cambio de hora en 2021". Nota de Prensa. Parlamento Europeo, 26 marzo 2019. 


\subsection{Otras obras y artículos}

- “Cambio de hora: una medida que Europa quiere eliminar", en El País, 26 octubre 2019.

- Clínica del sueño Estivill (Instituto Universitario Dexeus, Barcelona): "Estadísticas del cambio horario" s/f.

- DOMÍNGUEZ, M., “¿Tiene el cambio horario las horas contadas?”, en EITB, 24 de octubre 2020.

- GÁMEZ MEJÍAS, M.M., "Origen, evolución y futuro de la determinación normativa de la hora legal en España y la Unión Europea", en Revista de Administración Pública (Madrid), no 177 (Septiembre - diciembre 2008) 377-417: https://dialnet.unirioja.es/descarga/articulo/2798334.pdf.

- IBÁÑEZ SALAS, J.L., La Historia el relato del pasado. Silex, Madrid 2020.

- JIMÉNEZ, J., "Qué fue de la anunciada muerte del horario de verano: pese a los anuncios de Europa, seguiremos cambiando la hora dos vez al año", 16 octubre 1919: https://www.xataka.com/energia/que-fue-anunciada-muerte-horarioverano-pese-a-anuncios-europa-seguiremos-cambiando-hora-dos-vez-al-ano.

- OSUNA, I., "Saber vivir TVE”, 23 octubre 2020.

- PLANESAS, P., "La hora oficial en España y sus cambios", en Anuario del Observatorio Astronómico de Madrid, 2013, pp. 373-404:

http://astronomia.ign.es/rknowsys-theme/images/webAstro/paginas/documentos/ Anuario/lahoraoficialenespana.pdf.

- R.D., "Cambio al horario de invierno: el domingo 25 de octubre a las 3 serán las 2", en Diario de Sevilla, 23 octubre 2020.

- SÁNCHEZ, A., "Bruselas propondrá la desaparición del cambio de hora en la UE", en El País, 31 agosto 2018.

- SERVIMEDIA, España tiene seis meses para escoger entre horario de invierno o de verano, 26 octubre 2019.

- VIDALES, R., “En España, siempre con <jet lag>”, en El País, 26 septiembre 2013.

- VILAR, P., Iniciación al vocabulario del análisis histórico. Crítica, Barcelona 1980. 
- WIKIPEDIA: Horario de verano

- WIKIPEDIA: Horario de verano en el mundo.

- https:/cambiohorario.com/origenes/

- https://cambiohorario.com/pros-contras/

\begin{tabular}{|c|c|c|c|c|c|c|c|}
\hline \multicolumn{8}{|c|}{ VARIACIONES DEL HORARIO OFICIAL ESPAÑOL. } \\
\hline AÑO & $\begin{array}{c}\text { Adelanta } \\
1 \text { hora }\end{array}$ & Hora & $\begin{array}{c}\text { Atrasa } \\
1 \text { hora }\end{array}$ & & $\begin{array}{c}\text { Gaceta de } \\
\text { Madrid }\end{array}$ & Fecha & Página \\
\hline 1918 & 15 abril & 23.00 & 6 octubre & 24 & 94 & 04-04 & 26 \\
\hline 1919 & 6 abril & 23.00 & 6 octubre & & 88 & $29-03$ & $1217-1218$ \\
\hline 1924 & 16 abril & 23.00 & 5 octubre & & 99 & $08-04$ & 178 \\
\hline 1926 & 17 abril & 23.00 & 2 octubre & 24 & 100 & $10-04 /$ & 194 y195 \\
\hline 1927 & 9 abril & 23.00 & 1 octubre & 24 & 83 & $24-03$ & 1706 \\
\hline 1928 & 14 abril & 23.00 & 6 octubre & 24 & 92 & $01-04$ & 4 \\
\hline 1929 & 20 abril & 23.00 & 6 octubre & 24 & 107 & $17-04$ & 295 \\
\hline 1931 & 9 marzo & 23.00 & & & 106 & $16-04$ & $200-201(3)$ \\
\hline \multirow[t]{2}{*}{1931} & 18 abril & 23.00 & 4 octubre & & 70 & $11-03$ & 1344 \\
\hline & & & & & $\begin{array}{c}\text { Boletín } \\
\text { Oficial del } \\
\text { Estado }\end{array}$ & & \\
\hline \multicolumn{8}{|l|}{1936} \\
\hline (1)1937 & 22 mayo & 23.00 & 2 octubre & & BOE 210 & $18-04$ & No legible \\
\hline (2)1937 & 16 junio & 23.00 & 6 octubre & & GM 159a & $08-06$ & 1113 \\
\hline (1)1938 & 26 marzo & 23.00 & 1 octubre & & BOE 516 & $21-03$ & 6354 \\
\hline (2)1938 & 2 abril & 23.00 & 2 octubre & & $\mathrm{a}$ & & \\
\hline (2)1938 & 30 abril & 23.00 & 3 octubre & & & & \\
\hline 1939 & 15 abril & 23.00 & 7 octubre & 24 & $94 / 278$ & $04-04 / 05-10$ & $1926 / 5585$ \\
\hline 1940 & 16 marzo & 23.00 & No se atrasa & & 68 & 8 marzo 1940 & $1675-1676$ \\
\hline 1942 & 2 mayo & 23.00 & 1 septiembre & 01.00 & $122 / 241$ & $02-05 / 29-08$ & $3114 / 6575$ \\
\hline 1943 & 17 abril & 23.00 & 2 octubre & 01.00 & $84 / 253$ & $25-03 / 10-09$ & $2641 / 8777$ \\
\hline 1944 & 15 abril & 23.00 & 30 septiembre & 01.00 & $82 / 258$ & $22-03 / 14-09$ & $2388 / 6780$ \\
\hline 1945 & 14 abril & 23.00 & 30 septiembre & 01.00 & $88 / 255$ & $24-03 / 12-09$ & $2285 / 1694$ \\
\hline 1946 & 13 abril & 23.00 & 29 septiembre & 01.00 & $84 / 250$ & $25-03 / 7-09$ & $2296 / 6743$ \\
\hline 1949 & 30 abril & 23.00 & 1 octubre & 01.00 & $116 / 273$ & $6-04 / 20-09$ & $1894 / 4009$ \\
\hline 1974 & 13 abril & 23.00 & 6 octubre & 01.00 & $83 / 226$ & 06-04/20-09 & $7078 / 19311$ \\
\hline 1975 & 12 abril & 23.00 & 5 octubre & 01.00 & 60 & $11-03-1975$ & 4992 \\
\hline 1976 & 27 marzo & 23.00 & 26 septiembre & 01.00 & 72 & $24-03-1976$ & 5930 \\
\hline 1977 & 2 abril & 23.00 & 24 septiembre & 01.00 & 61 & $12-03-1977$ & 5756 \\
\hline 1978 & 2 abril & 02.00 & 2 octubre & 03.00 & 69 & $22-03-1978$ & 6775 \\
\hline 1979 & 1 abril & 02.00 & 30 septiembre & 03.00 & 55 & $05-03-1979$ & 5677 \\
\hline 1980 & 6 abril & 02.00 & 28 septiembre & 03.00 & 46 & $22-02-1980$ & 4151 \\
\hline 1981 & 29 marzo & 02.00 & 27 septiembre & 03.00 & & & \\
\hline 1982 & 28 marzo & 02.00 & 26 septiembre & 03.00 & 50 & $27-02-1982$ & 5230 \\
\hline 1983 & 27 marzo & 02.00 & 25 septiembre & 03.00 & 48 & $25-02-1983$ & 5476 \\
\hline
\end{tabular}




\begin{tabular}{|c|c|c|c|c|c|c|c|}
\hline \multicolumn{8}{|c|}{ VARIACIONES DEL HORARIO OFICIAL ESPAÑOL. } \\
\hline AÑO & $\begin{array}{l}\text { Adelanta } \\
1 \text { hora }\end{array}$ & Hora & $\begin{array}{l}\text { Atrasa } \\
1 \text { hora }\end{array}$ & & $\begin{array}{l}\text { Boletín } \\
\text { Oficial del } \\
\text { Estado }\end{array}$ & Fecha & Página \\
\hline 1984 & 25 marzo & 02.00 & 30 septiembre & 03.00 & 50 & $28-02-1984$ & 5366 \\
\hline 1985 & 31 marzo & 02.00 & 29 septiembre & 03.00 & 6 & $07-01-1985$ & 358 \\
\hline 1986 & 30 marzo & 02.00 & 28 septiembre & 03.00 & 15 & $17-01-1986$ & 2380 \\
\hline 1987 & 29 marzo & 02.00 & 27 septiembre & 03.00 & 17 & $20-01-1987$ & 1543 \\
\hline 1988 & 27 marzo & 02.00 & 25 septiembre & 03.00 & 26 & $30-01-1988$ & $3317-3318$ \\
\hline 1989 & 26 marzo & 02.00 & 24 septiembre & 03.00 & 56 & 07-03-1989 & 6386 \\
\hline 1990 & 25 marzo & 02.00 & 30 septiembre & 03.00 & 42 & $17-02-1990$ & 4775 \\
\hline 1991 & 31 marzo & 02.00 & 29 septiembre & 03.00 & 42 & $17-02-1990$ & 4775 \\
\hline 1992 & 29 marzo & 02.00 & 27 septiembre & 03.00 & 42 & $17-02-1990$ & 4775 \\
\hline 1993 & 28 marzo & 02.00 & 26 septiembre & 03.00 & 290 & 3-12-1992 & 41058 \\
\hline 1994 & 27 marzo & 02.00 & 25 septiembre & 03.00 & 290 & $3-12-1992$ & 41058 \\
\hline 1995 & 26 marzo & 02.00 & 24 septiembre & 03.00 & 304 & $21-12-1994$ & 38276 \\
\hline 1996 & 31 marzo & 02.00 & 27 octubre & 03.00 & 304 & 21-12-1994 & 38276 \\
\hline 1997 & 30 marzo & 02.00 & 26 octubre & 03.00 & 304 & 21-12-1994 & 38276 \\
\hline 1998 & 29 marzo & 02.00 & 25 octubre & 03.00 & 287 & $01-12-1997$ & 35339 \\
\hline 1999 & 28 marzo & 02.00 & 31 octubre & 03.00 & 287 & 01-12-1997 & 35339 \\
\hline 2000 & 26 marzo & 02.00 & 29 octubre & 03.00 & 287 & 01-12-1997 & 35339 \\
\hline 2001 & 25 marzo & 02.00 & 28 octubre & 03.00 & 287 & 01-12-1997 & 35339 \\
\hline 2002 & 31 marzo & 02.00 & 27 octubre & 03.00 & 53 & 02-03-2002 & 8617 a 8619 \\
\hline 2003 & 30 marzo & 02.00 & 26 octubre & 03.00 & 53 & $02-03-2002$ & 8617 a 8619 \\
\hline 2004 & 28 marzo & 02.00 & 31 octubre & 03.00 & 53 & $02-03-2002$ & 8617 a 8619 \\
\hline 2005 & 27 marzo & 02.00 & 30 octubre & 03.00 & 53 & 02-03-2002 & 8617 a 8619 \\
\hline 2006 & 26 marzo & 02.00 & 29 octubre & 03.00 & 53 & $02-03-2002$ & 8617 a 8619 \\
\hline 2007 & 25 marzo & 02.00 & 28 octubre & 03.00 & 164 & $11-07-2006$ & 25922 \\
\hline 2008 & 30 marzo & 02.00 & 26 octubre & 03.00 & 164 & $11-07-2006$ & 25922 \\
\hline 2009 & 29 marzo & 02.00 & 25 octubre & 03.00 & 164 & $11-07-2006$ & 25922 \\
\hline 2010 & 28 marzo & 02.00 & 31 octubre & 03.00 & 164 & $11-07-2006$ & 25922 \\
\hline 2011 & 27 marzo & 02.00 & 30 octubre & 03.00 & 164 & $11-07-2006$ & 25922 \\
\hline 2012 & 25 marzo & 02.00 & 28 octubre & 03.00 & 250 & $17-10-2011$ & 108246 y 108247 \\
\hline 2013 & 31 marzo & 02.00 & 27 octubre & 03.00 & 250 & $17-10-2011$ & 108246 y 108247 \\
\hline 2014 & 30 marzo & 02.00 & 26 octubre & 03.00 & 250 & $17-10-2011$ & 108246 y 108247 \\
\hline 2015 & 29 marzo & 02.00 & 25 octubre & 03.00 & 250 & $17-10-2011$ & 108246 y 108247 \\
\hline 2016 & 27 marzo & 02.00 & 30 octubre & 03.00 & 250 & $17-10-2011$ & 108246 y 108247 \\
\hline 2017 & 26 marzo & 02.00 & 29 octubre & 03.00 & 50 & $28-02-2017$ & 13850 y 13851 \\
\hline 2018 & 25 marzo & 02.00 & 28 octubre & 03.00 & 50 & $28-02-2017$ & 13850 y 13851 \\
\hline 2019 & 31 marzo & 02.00 & 27 octubre & 03.00 & 50 & $28-02-2017$ & 13850 y 13851 \\
\hline 2020 & 29 marzo & 02.00 & 25 octubre & 03.00 & 50 & $28-02-2017$ & 13850 y 13851 \\
\hline 2021 & 28 marzo & 02.00 & 31 octubre & 03.00 & 50 & $28-02-2017$ & 13850 y 13851 \\
\hline
\end{tabular}

(1) Boletín Oficial del Estado

(2) Gaceta de Madrid

(3) Orden Circular de la Presidencia del Gobierno provisional de la

República ANULA el adelanto horario

Fuente: Elaboración propia. 